\title{
Research of noise emission sources in railway transport and effective ways of their reduction
}

\author{
Peter Zvolenský ${ }^{*}$, Juraj Grenčík ${ }^{1}$, Alžbeta Pultznerová $^{2}$ and Lubomír Kašiar ${ }^{1}$ \\ ${ }^{1}$ University of Žilina, Faculty of Mechanical Engineering, Univerzitná 8215/1, 01026 Žilina, Slovakia \\ ${ }^{2}$ University of Žilina, Faculty of Civil Engineering, Univerzitná 8215/1, 01026 Žilina, Slovakia
}

\begin{abstract}
In the EU conditions attention is systematically paid to noise reduction on the railways. Because TSI rules systematically tighten limits for noise emissions from railway vehicles, noise research must be addressed by all Member States, as the main technical solutions for railway vehicles and construction technological aspects of railway operations can result in lower noise exposure of affected areas or objects. The paper focuses on theoretical investigation of sources and paths of sound propagation, possibilities of noise reduction both on vehicles and by infrastructure and experimental measurements of the situation in transport practice. Methodology for reducing railway noise around tracks has been presented, too.
\end{abstract}

\section{Introduction}

Environmental aspects of design, operation and maintenance of vehicles in recent years have gained particularly important significance. Under the conditions of the EU for long time systematically attention has been paying to rail noise reduction. Because TSI rules systematically have been tightening limits for noise emissions produced from railway vehicles, noise research must be addressed by all Member States. The main technical solutions for rolling stock and technological aspects of railway operations should result in lower noise exposure of affected areas or objects. Scientific approach in this area can be defined at several levels: a theoretical investigation of the source and paths of sound propagation, simulation and modelling of noise fields and their impact on the environment, verification of the theory and computer modelling by experimental research and verification of the situation in the transport practice, elaboration of procedures and methods for reduction of noise in the application for the design of specified railway vehicles as well as construction of railway tracks.

Noise reduction on the railway requires a systematic approach therefore continuous research of the aforementioned interconnected levels being the system components. In the transport practice, tasks associated with noise reduction usually appear in two equal time phases. Either as an urgent acute noise reduction, this usually arises from the measured situations - noise exposure, especially surveyed by the state regulatory authority, for example noise in railway hump yards affecting residential areas - or as a conceptual task

* Corresponding author: peter.zvolensky@,fstroj.uniza.sk 
resulting from the EU legislation and EU environmental policy of country concerned, for example concept of train formation and international transit so called silent trains [1].

Many designs of railway vehicles are on their design limits in terms of noise emissions and possibilities of their reduction. Equally solutions of the secondary noise reduction (acoustic barriers) are relatively well developed and parameters of sound reduction index and sound absorption are well-defined. So every additional noise reduction, even of only a few decibels is welcome, because for different acoustic conditions the maximum limits permitted by norms are often exceed just by few decibels. At the same time the use of materials and technologies that effectively encourage recycling has special significance Rapid transfer of scientific - research findings and results, particularly experimental research in the field of noise emissions from railway vehicles in transport practice, bring new tools and approaches to effective improvement of environmental quality

Development and modernization of railways in the Slovak Republic leads to targeted integration into European transport networks. This naturally means that high level of quality of transport, structures and vehicles is desired. When evaluating the rolling stock, among others, the emitted noise and vibration are assessed. The most dominant source of noise in the railway vehicle operation is a rolling of the wheel on the rail. We talk about so called combined noise resources, which are caused by roughness wheel and rail roughness and the produced by dynamic shocks of tracks and vehicles. Braking of the vehicles is another important noise source. When measuring and evaluating various parameters, it is important to comply with the provisions of the TSI. [2]

In the reduction of noise and vibration in transport it is most efficient to focus on their source and generally by active design modifications. Only when these primary possibilities cannot be use it is possible to use passive protection. If there is an urgent need to protect the environment, system of verification of compliance with the parameters of noise and vibration must be properly created. Their reduction represents a large and complex approach and proposals for solutions. Therefore the effects of noise and vibration are analysed separately, because they influence in different way the staff and a passengers on vehicles, and in different way people living in residential areas.

\section{Noise emitted by railway vehicles}

Sources of external noise from railway operations can be divided into several categories.

Primary noise - noise during movement of rolling stock

- basic - caused by rolling of wheel on rail

- other - noise from traction and auxiliary machines, air turbulence, noise produced by running gear, from pantographs and certainly vibrations of individual parts of vehicles.

Secondary - signals form locomotive, noise from shunting operations.

The basic source of noise is the wheel running on a rail - contact surface between wheel and rail. At this contact point, irregularities on the running surface of the wheel and so called transverse and longitudinal waves on the rail head produce oscillation of track and the vehicle and vibrations are generated, which are emitted to the air in the form of noise, or transmitted in the rail and wheel. From there the noise is propagated further in the construction or is radiated into the surrounding outer space. Sound waves are then propagated form a vehicle to surroundings, while the shape of the acoustic field is affected by:

- directional characteristics of noise source radiation,

- acoustic properties of the environment through which the emitted energy propagates,

- barriers in the path of noise propagation. 


\subsection{Noise reduction measures on railway vehicles}

Active noise protection measures are such modifications of noise sources that will reduce the overall noise, such as structural modifications of railway vehicles, optimization of track alignment and structural arrangement of railway lines and the like.

For railway vehicles, whether traction or wagons, it is possible to reduce noise emissions by the following design measures [1]:

- Traction vehicle (locomotive) - where besides noise produced by rolling of wheel on rail, noise generated by traction and auxiliary aggregates is added. In general, electric traction is less noisy than diesel traction. Diesel engine noise is usually reduced using exhaust silencers of diesel locomotives.

- Railway wagon - differences between the running noise passenger and freight wagons are attributed to more efficient damping adjustments on coaches as flexible suspension of car body on bogies, introduction of new bearings with lower rolling resistance, and the like.

- Appropriate type of brakes - trends is replacement tread brake for disk brakes with an anti-skid device. In case of tread brakes used on freight wagons, new materials of brake shoes are being developed, such as composite that replaces classical cast iron material. Brake shoes made from composite substantially reduce squeal sound during braking.

- Optimisation of wheel shape - it is possible to achieve certain minimum noise and vibration emissions of a wheel. It is possible to achieve this also by wheel profile and axial symmetry of the wheel.

- Using wheel noise absorber - which reduces not only noise radiation yet it transforms it into higher frequency range and reduces noise level compared with conventional wheel by about $6 \mathrm{~dB}$

- Shading cover - mounted on car body, it can be placed also o bogies, which contributes to reduction of emitted noise.

- Aerodynamic shape of car body - at higher velocities the aerodynamic shape of car body is important. It reduced remarkably irregularities on outer surface of car body and excess edges. By this uncontrollable turbulence on car body surface is reduced.

- Suitable pantograph type design - electric current pantograph is significant noise source at higher operational velocities.

\section{Railway noise around railway tracks}

Because most of the railway lines were built in the territory of the Slovak Republic in the 19 th and the beginning of the $20^{\text {th }}$ century, the question of the noise was not solved in their design and construction and therefore no arrangements for its reduction were implemented. Currently on the railway lines of the main corridor Košice - Žilina - Bratislava modernization of railway track, connected with the transition to a qualitatively new, higher standard is underway. This enables trains rung on upgraded lines at speed up to $160 \mathrm{~km} / \mathrm{h}$. These changes, however, will have impact on the environment. Among the biggest impacts of rail transport on the environment belong noise and vibrations and their impact on people living near the railway line.

\subsection{Noise from the aspect of railway track alignment}

Natural protection against traffic noise is longer distance of the noise source from residential buildings, which can be accomplished only in case of new lines construction. 
For the design of new railway lines, especially high-speed, light rail and rapid lines, it is possible to reduce the noise load by using the following options [2, 3]:

- Tunnel line - most suitable for densely built-up area from the environmental protection point of view; near the tunnel line, however, buildings may be affected by vibrations (i.e. underground in large cities, eventual connecting lines of suburban and long-distance passenger traffic through the city centre).

- Deep cut - attenuates noise,

- $\quad$ Line above terrain level on embankment body - requires building-up an embankment with moderate slope gradient with noise protection berries and growing vegetation of bushes and trees which creates natural noise insulation and non-violent separation of traffic on the route from city life is achieved.

- Line construction on elevated lines - is noisier and more difficult solution for inclusion into countryside or residential area.

The most suitable technical solution of communication from the acoustic aspect is routing the line in a cut or tunnel. The least suitable is construction on the terrain level. It is very suitable in case of re-buildings, eventually new-built constructions, to locate road communication and railway line parallel in so called transport corridor and adjacent area protect by earth walls and higher greenery.

\subsection{Noise from the track construction aspect}

From the perspective of a railway line, it is possible to reduce noise levels by optimum directional and altitude alignment, sufficiently deformation resistant structure of railway substructure, by applying modern structures of the superstructure - such as continuous welded rail, resilient fixation of rails, anti-vibration mats and flexible pads, suitable design of the rails, applying modern types of switches, application rail absorbers, by suitable design of bridges and last but not least by regular and continuous maintenance of the superstructure [4].

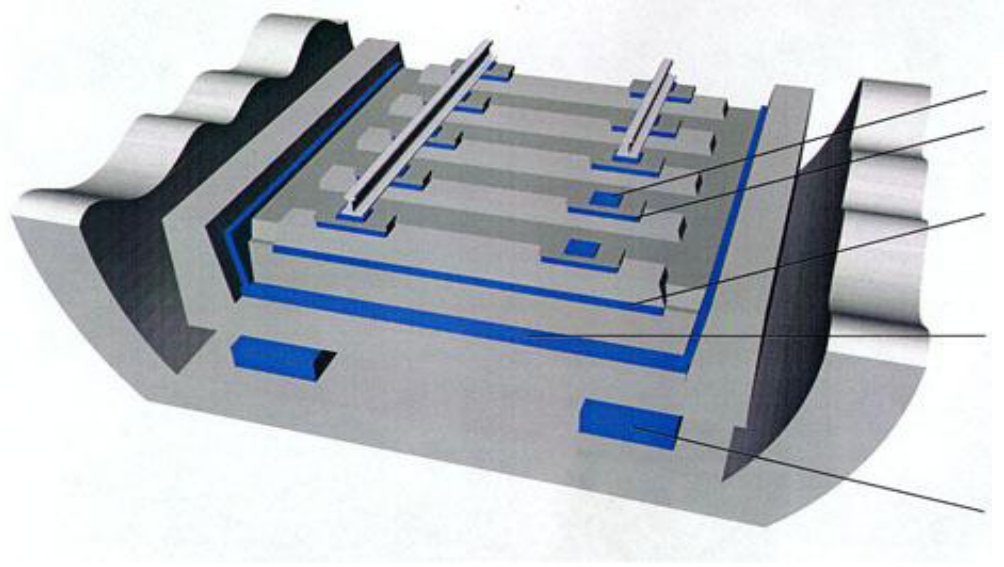

Rail Pad

Baseplate Pad

Sleeper Pad

Ballast Mat

alternativ : Full

Surface Bearing

Elastic Bearing for Slab Track

Fig. 1. Resilient railway fastenings [5].

\section{Possibilities of noise reduction on railway tracks}

Noise reduction generated from rail transport on already built-up track can be done by direct design solutions for the railway track - so called active noise abatement solutions or by constructing of sufficiently noise reducing barriers - so called passive noise solutions. 


\subsection{Active noise abatement solutions}

Noise barriers in many cases help to significantly reduce the load on citizens by noise from traffic, but this solution is not always possible to be used to achieve maximum success. If necessary, preserving free sight, aesthetics and needs only for minor additional noise reduction, active noise solutions are preferred. Their advantage is that they prevent the spread of noise to the surrounding area. An option is using a rail absorber and so-called rail track absorber (rail mat).

Rail damper (absorber) is fixed to the rail web. Thanks to its design composition it has high absorption properties by which it absorbs vibrations arising at the wheel / rail interface and thereby prevents the generation of noise in the rail. In the case of a train run, in the contact between wheel and rail noise with variable spectrum is generated. Rail damper works on the system of vibrations absorption at frequencies with the greatest noise levels. For low and high frequencies, which correspond to lower noise levels, the structure of the rail damper is designed so that the damper had no effect on the noise generated. On the other hand, in the case of frequencies that are characteristic for most of the noise generated, the rail damper is the most efficient [6]. Rail damper that prevents the propagation of the vibration wave also facilitates its better attenuation.

There are several types of rail dampers that are different in shape and design structure. One of models manufactured by Vossloh company is shown in Fig. 2 and 3.

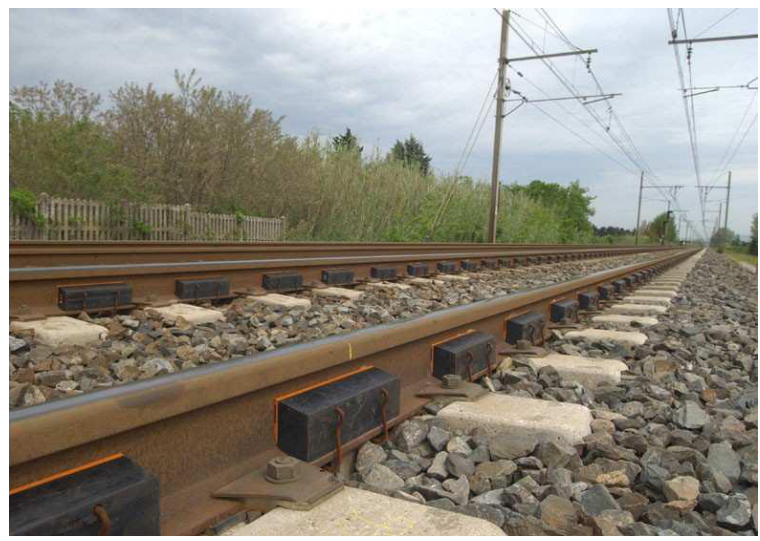

Fig. 2 Rail damper of Vossloh [6].

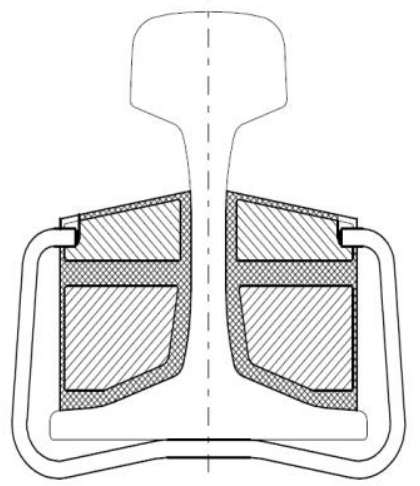

Fig. 3 Cross-section of rail damper [6].

Rail dampers reduce noise generally by about $1-3 \mathrm{~dB}$, when well designed by 4-7 dB [6]. Their main advantage is that they can be mounted even after the construction of the section in critical locations for improving the noise parameters after putting construction into operation, there are no restrictions on track maintenance, they are maintenance-free and the rail damper does not interfere with the overall appearance of the track [4].

Track absorber is a system mats made from wooden-cemented parts Duris, or recycled synthetic material STERED ${ }^{\circledR}$ (Fig. 4)a thickness of 50 to $150 \mathrm{~mm}$, and its design follows the corresponding shape of the tracks, whether it is for new construction or reconstruction of existing railway lines. [7] It consists of 5 types of absorbers, which are placed between the rails and next to them, while the combination significantly reduces noise from rail traffic (Fig. 5). Based on measurements by accredited laboratory, the compact system components in case of the standard audio spectrum in rail transport, achieves absorption up to $18 \mathrm{~dB}[8]$. 


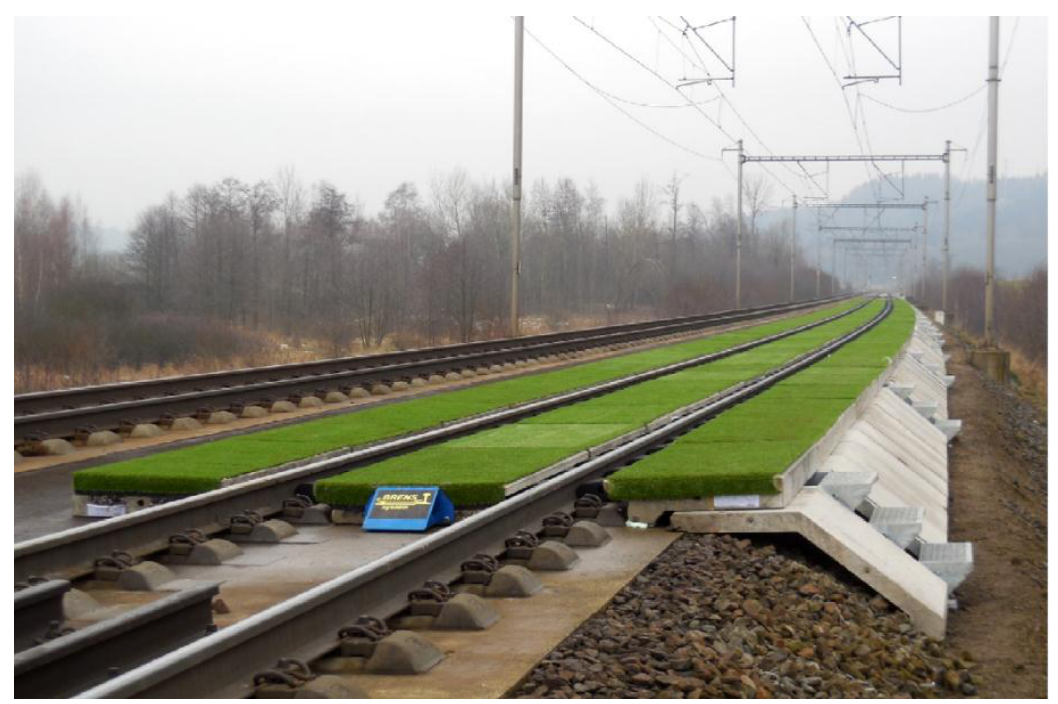

Fig. 4. Completed track absorber BRENS ${ }^{\circledR}$ with synthetic recyclate STERED ${ }^{\circledR}$ and artificial grass on the [7].

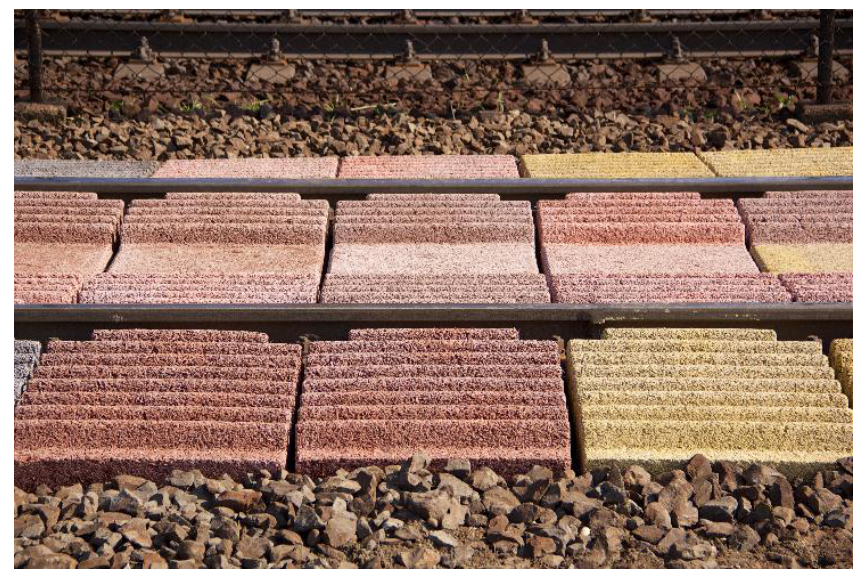

Fig. 5. Track noised absorber [8].

\subsection{Passive noise reduction solutions}

The purpose is to build an acoustically sufficient impermeable noise barrier built on the propagation path of sound waves, while a sound shadow of sound pressure levels is created behind the barrier. Such barrier may be a physical object, earth walls, vegetation and the most commonly used anti-noise walls.

Noise barriers nowadays are the most common structure utilized to reduce the noise already generated. They are constructed in parallel with modernization of railway corridors by comparing the permissible noise limit values according to [9] with the noise emission values determined by noise studies, detailed calculations of isophones (noise exposure contours) and verification measurements. Their elaboration is required by the proposed increase of line speed on upgraded sections of railway track to $160 \mathrm{~km} / \mathrm{h}$. 
The efficiency of a noise barrier depends on structural elements, materials, shape (Fig. 6 and 7), height, length, location on the area and the quality of the construction corresponding to needs of the particular situation.

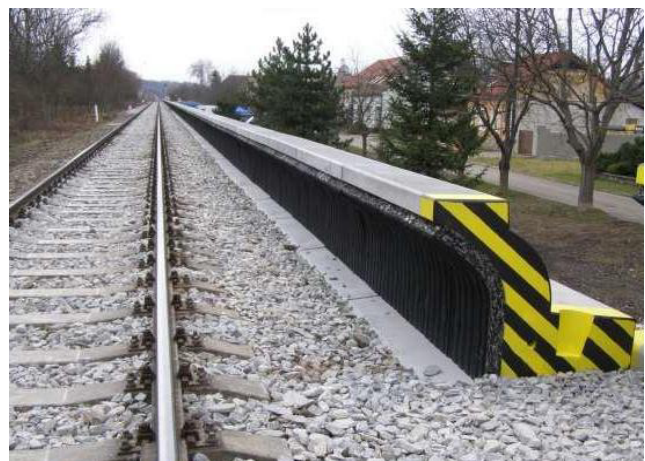

Fig. 6 Low noise barrier [10].

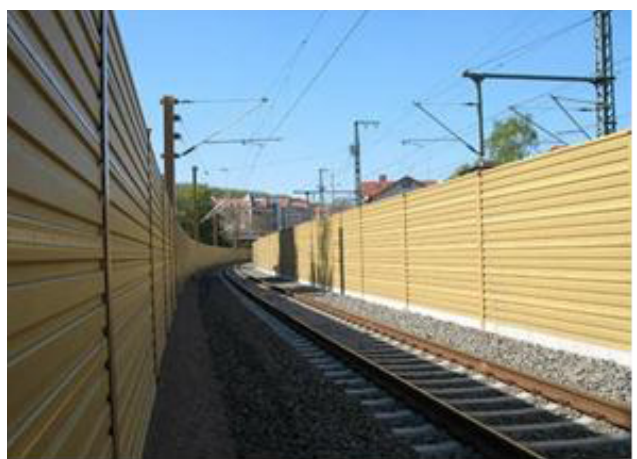

Fig. 7 track barrier [11].

\section{Methodology for noise reduction on railways}

For consistent design of noise prevention measures, especially location, dimensions and acoustic properties of noise barriers and measures on the buildings themselves, it is appropriate to make predictive mathematical modelling of sound propagation in the area of interest. This requires the methodology as follows: [12]

1. Specification of the area of interest - a user-defined polygon, which delimits the assessed area. Area of interest is defined by a strip (region) with a width of at least 100 $\mathrm{m}$ from the route of the railway line.

2. Creation of a digital terrain model - definition of terrain and objects (buildings) is formed on the basis of data from aerial photography.

3. Definition of railway communications - size, shape, character of trains' run, quality of the superstructure and the like.

4. Design of noise barriers - at this stage 3D dimensions of all objects, acoustic properties of the walls and the height of the walls are determined.

5. Modelling the proposed route of the railway line - using software for predicting noise immissions in the exterior, all elements of the proposed routes - bridges, overpasses, cuts, embankments, elevated highways, and so on are modelled.

6. Input of the expected number and types of trains, their speeds, lengths, run character and so on.

7. Calibration of the mathematical model - based on calibration measurements, the model is calibrated so that to ensure the necessary accuracy of modelling results.

8. Mathematical modelling - calculation of noise immissions in the area of interest. The objective is to develop a noise map of the area of the railway section using methods of mathematical modelling, using a methodology for traffic noise modelling in accordance with the valid Slovak legislation and the relevant norms. Example of noise map after application of the anti-noise wall is in Fig. 8.

9. Optimization of noise barriers - designed noise barriers will be optimized so that the permissible values determining the quantities of noise in accordance with applicable legislation have not been exceeded on the area of interest.

10. Proposal of other technical arrangements - arrangements for construction projects 


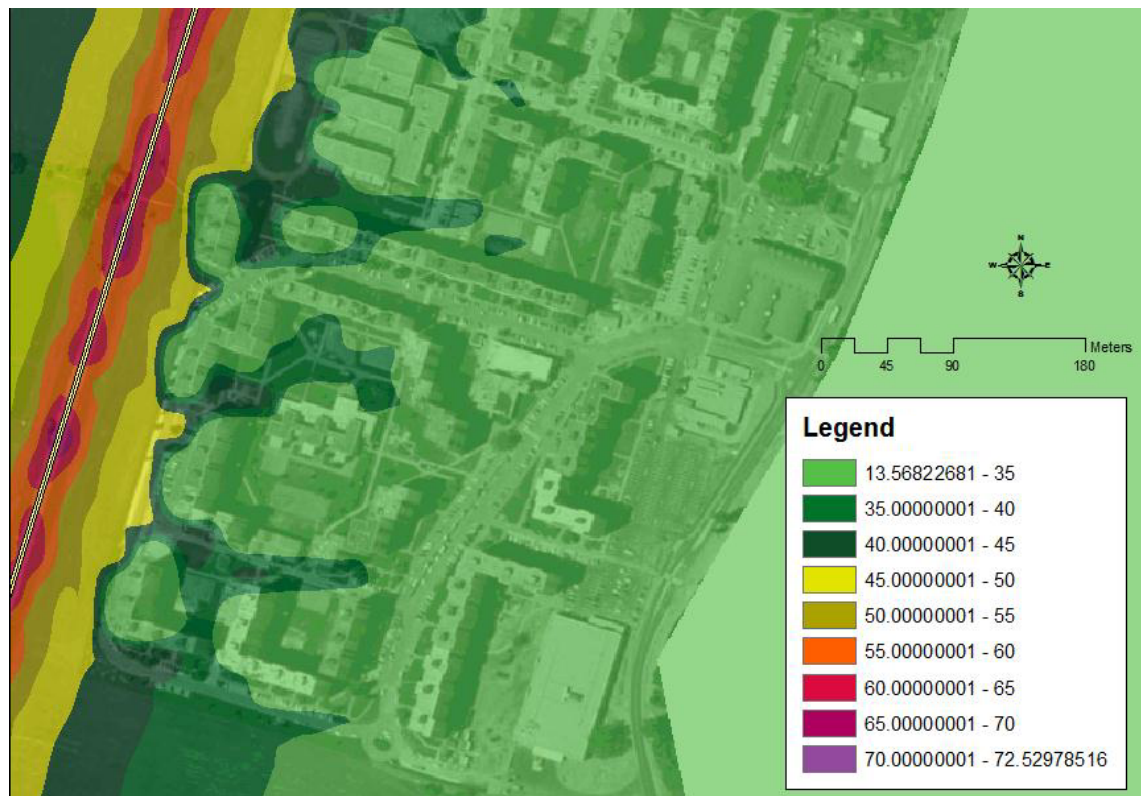

Fig. 8. Visualization of continuous sound propagation generated from a modernized railway line the specified area with highlighting of polygons in 3D (own research).

\section{Practical example - noise analysis at hump marshalling yard}

Particularly unfavourable acoustic situation arises in formation of freight train using technology of shunting at so-called hump marshalling yards using track retarders for braking. The braking performance of these retarders is generated automatically by clamping special jaws on the railway vehicle wheel according to the weight and the running speed of shunted freight wagons, while extremely high noise levels are generated, often exceeding $120 \mathrm{~dB}(\mathrm{~A})$. Rather extensive research is focused on this problem area, both on the experimental analysis of noise conditions, computer simulations of noise propagation fields and propagation paths of noise, and also the proposals for noise control solutions. As an example acoustic situation during braking of shunting freight tank wagons series Zaes with use of track retarders (Fig. 9, 10, 11).

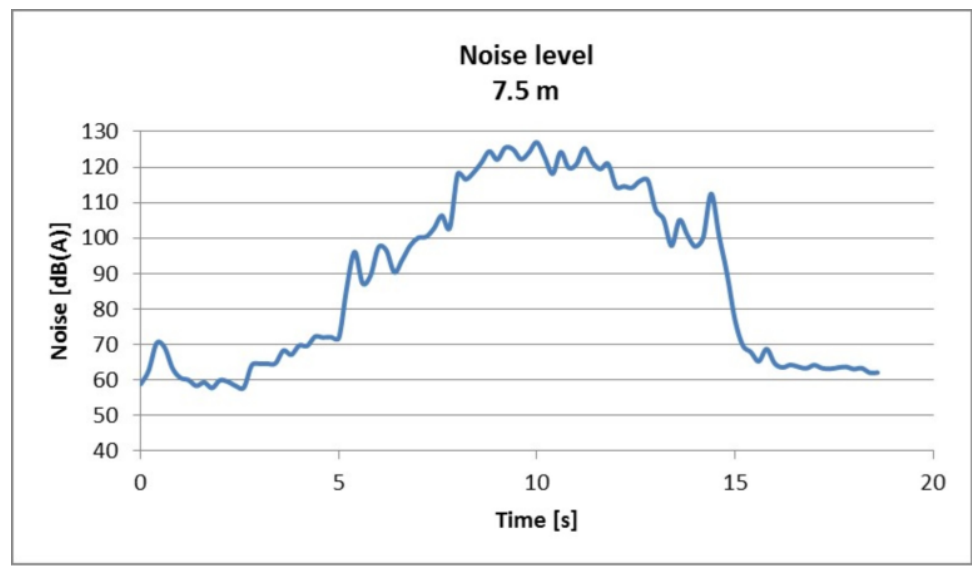

Fig. 9. Noise level at track retarder in the distance $7.5 \mathrm{~m}$ from track centre line (own research). 


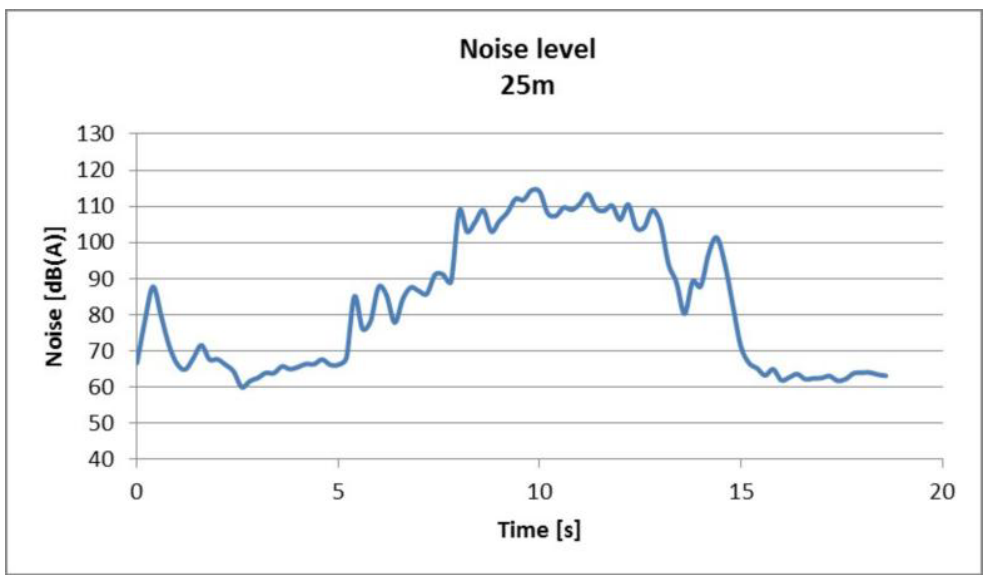

Fig. 10. Noise level at track retarder in the distance of $25 \mathrm{~m}$ from track centre line (own research).

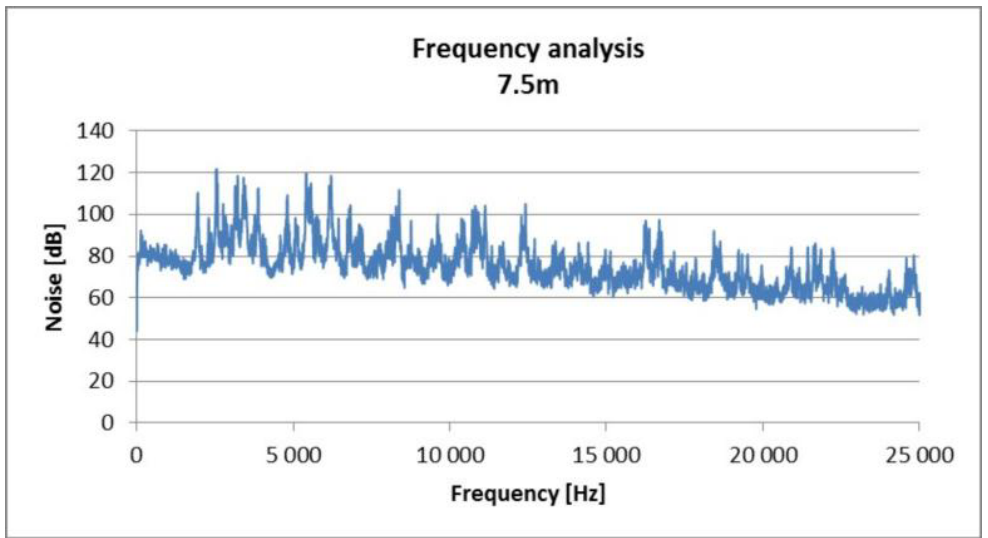

Fig. 11. Frequency analysis of noise at track retarder in the distance $7.5 \mathrm{~m}$ from track centre line (own research).

\section{Conclusions}

From a series of the measurements it implies that the different levels at the distance of 7.5 $m$ from track centre line reached enormous values more than $127 \mathrm{~dB}(\mathrm{~A})$. From the frequency analysis of noise measurements carried out it implies that up to $5000 \mathrm{~Hz}$ there are dominant tonal frequencies that exceed $120 \mathrm{~dB}$. There were also dominant noise frequencies found, which are: $1548 \mathrm{~Hz}$, in which the noise level was measured $124 \mathrm{~dB}$, $1624 \mathrm{~Hz}$ with $123 \mathrm{~dB}, 3288 \mathrm{~Hz}$ with $122 \mathrm{~dB}$. It is also interesting that with increased body weight of shunted wagons in the range of 66-78 tons, during the breaking by track retarder the dominant frequency range are moving from the higher to the lower frequencies.

Measurements have shown that the action of track retarders significantly creates noise burden over fairly large affected area. For this reason, in the program NoiseAtWork v3.32 we have simulated the propagation of the measured values of noise levels in the surrounding area. The simulation results show that the measured noise level with a value of $127 \mathrm{~dB}(\mathrm{~A})$ reaches $122 \mathrm{~dB}(\mathrm{~A})$ at the distance of $1000 \mathrm{~m}$ from the track retarder. This characterizes particularly unfavourable acoustic situation for wide surroundings of the hump marshalling yard technologies using track retarders. 
There are partial results of the grant VEGA 1/0766/15" Research of noise emissions sources in the railway transport and methods of their effective reduction" in the paper.

\section{References}

1. U. Clausen, C. Doll, F. J. Franklin, G. Vasic Franklin, H. Heinrichmeyer, J. Kochsiek, W. Rothengatter, N. Sieber, Reduction of noise pollution from rail transport, study, European Parliament (2012)

2. U. Degn, U. Danneskiold-Samsøe, A Study of European Priorities and Strategies for Railway Noise Abatement, Report II, Retrieval of System Cases, Bruxelles, EU Commision, Directorate - General for Energy and Transport, Belgium, (2001)

3. C. Esveld, Modern railway track (Delft University of Technology, The Netherlands, 2001)

4. L. Bavlna, A. Pultznerová, P. Zvolenský, Possibilities of railway traffic noise reduction depending on the railway structure and construction of the rail vehicle, Logistika 4 (2015)

5. https://www.getzner.com/de/ueber-uns/wer-wir-sind (10.3.2017)

6. D. Benton, Railway noise in urban areas, possible source noise reduction measures

7. http://www.stered.sk/novinka/kolajove-absorbery-hluku-brens-dalsi-prirastok-dorodiny-efektivnych-protihlukovych-rieseni-pre-zeleznice (10.3.2017)

8. http://www.leier.sk/hlukove-absorbery-a-nastupistne-hrany-durisol (10.3.2017)

9. Decree of MZ No. 549/2007 Z.z. stating the details on the permissible levels of noise, infrasound and vibration and the requirements on objectification of noise, infrasound and vibration in the environment of $16^{\text {th }}$ August 2007

10. https://www.google.sk/search?q=n\%C3\%ADzke+protihlukov\%C3\%A9+steny\&hl=sk \&rlz=1T4MXGB skSK563SK575\&tbm $=$ isch\&tbo $=u \&$ source $=$ univ\&sa $=X \& e i=T 4 C Z$ U8TqHYnY0QWC-YCYBA\&ved=0CFsQsAQ\&biw=1120\&bih=824 (10.3.2017)

11. https://www.google.sk/search? $\mathrm{q}=$ protihlukov $\% \mathrm{C} 3 \% \mathrm{~A} 9+$ steny\&tbm $=\mathrm{isch} \&$ tbo $=\mathrm{u} \&$ sour ce $=$ univ\&sa $=$ X\&ei $=$ Qn2ZU76gLJOM4gTcsIDIAg\&sqi $=2 \& v e d=0 C C s Q s A Q \& b i w=11$ $19 \&$ bih=824 (10.3.2017)

12. E. Lumnitzer, M. Bil'ová, Methodology for design of anti-noise measures in the vicinity of railway lines to ensure the acoustic quality of interiors, Nehnutel'nosti a bývanie, III, 1 (2015) 